\title{
Procollagen 1 N-Terminal Propeptide Measurement
}

National Cancer Institute

\section{Source}

National Cancer Institute. Procollagen 1 N-Terminal Propeptide Measurement. NCI

Thesaurus. Code C96625.

The determination of the amount of procollagen $1 \mathrm{~N}$-terminal propeptide present in a sample. 